\title{
Resenha do livro Variational Approach to Gravity Field Theories - From Newton to Einstein and Beyond
}

\author{
Variational Approach to Gravity Field Theories - From Newton to Einstein and Beyond - Book review
}

\author{
Alessio Gava*1@ \\ ${ }^{1}$ Universidade Estadual do Paraná, Apucarana, PR, Brasil.
}

Recebido em 24 de março de 2020. Revisado em 31 de maio de 2020. Aceito em 18 de junho de 2020.

\begin{abstract}
Apresenta-se uma resenha crítica do livro Variational Approach to Gravity Field Theories - From Newton to Einstein and Beyond (2017), de autoria do astrofísico italiano Alberto Vecchiato. Na obra, Vecchiato mostra que a física assim como a conhecemos pode ser construída a partir de modelos matemáticos simples, gradativamente complexificados ao introduzir novos princípios. O leitor é guiado, progressivamente, a percorrer os passos que conduzem da física clássica àquela relativística e a entender como isso acontece e quais são as motivações. Ademais, ao apresentar de modo claro e elegante a abordagem variacional às teorias de campo gravitacional, Vecchiato mostra uma preocupação constante em conduzir o leitor de forma que esse entenda o funcionamento e a relevância da técnica que o autor considera a mais poderosa e o conceito mais unificador da física teórica. Cada capítulo é enriquecido com exercícios, dos quais é oferecida uma resolução passo a passo, de modo que o leitor possa inteirar-se de fato do assunto apresentado e seguir a leitura de modo proveitoso O aspecto inovador do livro, porém, não é constituído pelo rigor e pela clareza da tratação da abordagem variacional, mas sim pelo ponto de vista que Vecchiato parece manter ao longo da obra e que leva o leitor a endossar também: a física é uma construção humana, sujeita a erro e suscetível de ser aperfeiçoada, e não um sistema completo e definitivo de verdades acerca do mundo.
\end{abstract}

Palavras-chave: abordagem variacional, antirrealismo, geometria, modelos, relatividade geral.

This is a critical review of the book Variational Approach to Gravity Field Theories - From Newton to Einstein and Beyond (2017), written by the Italian astrophysicist Alberto Vecchiato. In his work, Vecchiato shows that physics, as we know it, can be built up from simple mathematical models that become more complex step by step by gradually introducing new principles. The reader is invited to follow the steps that lead from classical physics to relativity and to understand how this happens and why. Moreover, while presenting the variational approach to gravity field theories in a clear and elegant manner, Vecchiato shows a constant worry in leading the readers in such a way that they understand the relevance of what the author considers to be the most powerful technique and unifying concept of theoretical physics - and how it works. Each chapter is enriched with exercises, of which a step-by-step solution is offered, so that the reader can gain a real insight into the topic presented and follow the reading as fruitfully as possible. The most innovative aspect of the book, however, is not the rigorousness and the clarity of the treatment of the variational approach but rather the point of view that Vecchiato keeps and that the reader is led to endorse too: physics is a human enterprise, prone to error and open to improvement, and not a complete and definite system of truths about our world.

Keywords: antirealism, general relativity, geometry, models, variational approach.

Variational Approach to Gravity Field Theories - From Newton to Einstein and Beyond é um livro em língua inglesa publicado em 2017 pela Springer em sua série Undergraduate Lecture Notes in Physics (ULNP), especialmente dedicada a abordagens inovadoras no ensino de física no nível de graduação. Particularmente, das obras da ULNP é esperado que apresentem: um tratamento excepcionalmente claro e sintético de algum assunto normalmente abordado em aulas de graduação; uma introdução consistente e sólida de tópicos avançados, para estudantes de graduação; uma nova perspectiva ou uma abordagem diferente no ensino.

Ao apresentar de modo claro e elegante a abordagem variacional às teorias de campo gravitacional, o livro objeto desta resenha, de autoria do astrofísico italiano Alberto Vecchiato, preenche as três características exigidas para poder fazer parte da ULNP (as obras dessa série devem satisfazer pelo menos uma delas), ao mesmo tempo que mostra uma preocupação constante em conduzir o leitor de forma que esse entenda o funcionamento

*Endereço de correspondência: alessiogava@yahoo.it 
e a relevância de "a técnica mais poderosa e o conceito mais unificador da física teórica" [1, p. vii] $]^{1}$

Como se sabe, o cálculo de variações corresponde ao estudo de minimização de funcionais, a saber, de funções reais definidas em espaços de funções - 'funções de funcões'. A física clássica pode ser apresentada de modo bastante eficiente, porém, até mesmo em nível universitário, sem recorrer a técnicas tão avançadas de cálculo, que poderiam diferentemente parecer sobremodo abstratas nesse contexto. Por essa razão, compreensivelmente, é incomum que a abordagem variacional seja apresentada de modo completo nos cursos de graduação em física - com exceção, talvez, dos formalismos lagrangeano e hamiltoniano.

O preço disso, afirma Vecchiato, é que ao enfrentar tópicos mais avançados, como a física quântica ou a relativística, e assim deparando-se com tais técnicas, que nesses contextos são extremamente eficazes e úteis - ou até mesmo necessárias -, o estudante corre o risco de não compreendê-las como se deveria, pois representam um modo de descrever a realidade física muito abstrato e nada familiar. A consequência é que se cria, desse modo, um hiato entre 'os leigos', incluindo nessa categoria até mesmo muitos físicos, e 'os especialistas', que usam métodos e falam uma linguagem acessível a poucos - o que de fato parece ser o caso no mundo inteiro.

Tal problema pode ser evitado - e o gap preenchido - ao revisar os conceitos da física clássica, uma vez que esses já tenham sido adquiridos, na perspectiva da abordagem variacional. O livro de Vecchiato pretende fazer isso enfrentando a questão do ponto de vista das teorias de campo gravitacional e enfatizando a continuidade, que a abordagem variacional torna clara, entre o domínio clássico e aquele relativístico.

De modo geral, a vantagem de trabalhar em uma perspectiva variacional fica muito mais evidente nas física relativística e quântica do que na clássica. Ainda assim, afirma o astrofísico italiano, é útil introduzir tais técnicas no panorama clássico por pelo menos três motivos:

Em primeiro lugar, isso torna muito mais simples a transição para a física relativística, pois permite adquirir familiaridade com as caracteristícas essenciais dessa nova linguagem ao vê-la em ação em um panorama já conhecido.

Além disso, a parte mais importante na formulação de uma nova teoria física reside frequentemente na mudança de alguns princípios básicos. Mesmo que a formulação lagrangeana da gravidade clássica pouco ou nada acrescente em relação à sua apresentação convencional, a formulação da física relativística na linguagem clássica é no mínimo complicada, ou até mesmo impraticável. A formula-

${ }^{1}$ Todas as citações presentes no texto são traduções do original (inglês ou italiano), realizadas pelo autor desta resenha. ção lagrangeana representa portanto a única possibilidade de se haver ambas as teorias descritas em uma linguagem comum, o que permite aprofundar de modo importante o entendimento de suas diferenças e similaridades em termos de seus princípios básicos.

Por fim, a formulação lagrangeana das teorias de campo providencia um modo simples e natural de encontrar extensões e/ou modificações para teorias já conhecidas. Com efeito, essa representa uma maneira comum de explorar novas possibilidades na física teórica. $[1$, p. 70$]$

Contudo, o cálculo de variações é apenas uma técnica, conquanto poderosa, e não deve ser esquecido que o significado físico das teorias reside em seus princípios básicos. Por essa razão, Vecchiato busca enfatizar de modo mais claro possível, em sua exposição, a ligação entre teorias e princípios no nível matemático mais fundamental.

O livro começa, até mesmo como 'aquecimento', com uma introdução aos princípios variacionais, utilizando a dinâmica newtoniana e a gravitação como 'estudos de caso'. Ao apresentar os conceitos e a linguagem do formalismo lagrangeano das teorias de campos, Vecchiato faz questão de mostrar que se trata de descrições alternativas daquilo que o leitor já conhece da física clássica. No que concerne à dinâmica, por exemplo, o princípio de mínima ação de Hamilton, que está na base da abordagem variacional, é equivalente à segunda lei de Newton, a famosa $F=m a$.

Em outras palavras, podem-se até adotar novas técnicas e novas linguagens no estudo e na descrição do mundo, mas os princípios-base de uma teoria não mudam ao mudar a maneira de apresentá-la - obviamente. Ainda assim, o modo em que os mesmos princípios são formulados pode ser determinante, ou seja, as perspectivas não são equivalentes, pois não têm o mesmo alcance. Com efeito, existe, como se sabe, uma inconsistência entre os princípios que estão na base da física clássica e o eletromagnetismo, dependendo de como esses são apresentados. Tal incosistência, porém, pode ser resolvida abandonando a forma galileiana do princípio de relatividade e adotando outra, o que acaba levando à física relativística.

Uma das características mais notáveis da abordagem variacional, diferentemente, é sua generalidade. Com efeito, tal técnica está baseada em um princípio simples, o qual afirma que as leis físicas compartilham da característica de minimizar a ação de um sistema, e isso pode ser aplicado a muitas teorias diferentes, sejam elas newtonianas ou relativísticas, clássicas ou quânticas [1, p. 23]

Mas o aspecto talvez mais interessante de Variational Approach to Gravity Field Theories é o fato de deixar muito claro ao leitor, desde o início, que as teorias físicas nada mais são do que modelos da realidade e que a 
geometria utilizada para traduzir os princípios que subjacem às mesmas em linguagem matemática depende da escolha de tais princípios. A própria geometria euclidiana, aliás, conforme Vecchiato salienta no capítulo dois, pode ser considerada uma teoria física e é assim que foi interpretada até pelo menos a época de Newton.

Ao longo do livro, Vecchiato mostra que a física assim como a conhecemos pode ser construída a partir de modelos matemáticos simples, gradativamente complexificados ao introduzir novos princípios. Mas isso requer, em alguns casos, lançar mão de novos sistemas geométricos e portanto de novos modelos - conforme acontece, como bem se sabe, com a relatividade einsteniana - e também de novas técnicas, como é o caso da abordagem variacional, que o autor considera ser a mais abrangente e adaptável.

Assim o leitor é guiado, progressivamente, a percorrer os passos que conduzem da física clássica àquela relativística, a entender as motivações que levam a abandonar determinados modelos em favor de outros, a compreender quais princípios-base e quais grandezas e leis queremos que se mantenham invariantes, até se chegar à relatividade geral. Tendo bem em mente que se trata apenas de modelos - que por essa mesma razão carregam sempre, inclusive, um certo grau de simplificação e de idealização. Vários foram substituídos, ao longo da história, por outros que foram considerados mais adequados. O mesmo destino, provavelmente, aguarda a teoria einsteniana: "a relatividade geral é como qualquer outra teoria científica: um modelo atualmente muito útil, que (...) um dia será substituído por outro melhor" [1, p. 239].

No último capítulo de sua obra, Vecchiato até aponta para alguns sinais de que esse parece ser mesmo o provavél destino da relatividade geral, pois: tal teoria está mostrando seus limites quanto a acuracidade em relação aos resultados experimentais; é notoriamente incompatível com a física quântica; não conseguiu englobar de forma satisfatória o princípio de Mach, o que era um dos desiderata de Einstein. Por essa razão, o autor ainda apresenta, nessa parte final do livro, algumas possíveis alternativas à teoria einsteniana.

Para enfrentar de modo adequado esse último capítulo, o décimo, que apresenta o sugestivo título "Beyond General Relativity", Vecchiato considerou oportuno expor anteriormente algumas aplicações da relatividade geral a problemas físicos significativos, tendo o cuidado de selecionar um número limitado de assuntos, que formam o capítulo nove, de modo que os mesmos se inserissem harmonicamente no discurso geral e constituíssem uma ponte entre os capítulos anteriores e o último.

Com efeito, as seções 9.1 e 9.2 retomam [o conteúdo de] o capítulo 7 , mostrando que a gravidade de Einstein dá conta das observações clássicas (excesso de shift do pericentro da órbita de Mercúrio, deflexão da luz) sem as contradições da gravidade como campo sobreposto a uma geometria minkowskiana, mas também que a mesma consegue prever fenômenos antes desconhecidos (buracos negros, ondas gravitacionais). Isso fornece a oportunidade de passar, na seção 9.3, a examinar a necessidade da verificação experimental e de um dos formalismos mais conhecidos nessa área de aplicação, na fronteira entre pesquisa teórica e experimento. O terreno assim está preparado para passar às soluções cosmológicas, as quais, retomando problemas citados anteriormante, como aqueles da matéria e da energia escuras, põem o leitor na direção certa para enfrentar o capítulo 10 (mensagem e-mail de 24 de março de 2020).

O aspecto inovador de Variational Approach to Gravity Field Theories, porém, não é constituído pelo rigor e pela clareza da tratação da abordagem variacional e nem pelo fato de o autor ter enriquecido cada capítulo com exercícios resolvidos passo a passo e detalhadamente, de modo que o leitor possa inteirar-se de fato do assunto apresentado e seguir a leitura de modo proveitoso, mas sim o ponto de vista que Vecchiato parece manter ao longo da obra e que leva o leitor a endossar também. Para o astrofísico italiano, está muito claro que a física se deu a tarefa de descrever e interpretar a realidade à nossa volta através da construção de modelos matemáticos cada vez mais sofisticados e abrangentes e não de 'nos dizer a verdade' acerca de como o mundo é.

Conforme já foi dito, desde o início o autor conduz o leitor a uma progressiva 'construção matemática' do mundo físico, assumindo assim uma perspectiva bem diferente daquela das obras que comumente se encontram na literatura (particularmente dos manuais escolares e universitários de física), que tendem a apresentar o mundo como se ele fosse realmente constituído da maneira como é descrito pelas teorias físicas.

Ao fazer isso, Vecchiato se aproxima, implicitamente, do debate contemporâneo em filosofia da ciência entre as posições conhecidas como realismo e antirrealismo. Nesse âmbito, parece haver um consenso, hoje em dia, acerca de as teorias físicas serem conjuntos de modelos matemáticos. A divergência surge em um segundo momento, quando da interpretação de tais modelos, que se interseca com uma diferente opinião acerca de qual seria o objetivo da ciência. Os chamados 'realistas' afirmam, grosso modo, que a ciência visa nos fornecer teorias que descrevam de modo correto a realidade ao nosso redor, até mesmo em seus aspectos inacessíveis aos nossos sentidos. Esse parece ser, conforme dito anteriormente, o ponto de vista implícito de quase todos os livros de física que os estudantes universitários acabam lendo em seus percursos de estudo.

Já a posição de Vecchiato parece aproximar-se da posição dos 'antirrealistas', particularmente daquela de Bas van Fraassen, o qual afirma que a atividade científica é uma atividade de construção de modelos matemáticos, que devem ser adequados aos fenômenos, e não de desco- 
berta daquilo que para nós seres humanos é inobservável [2, p. 5]. Essa consciência de que as teorias científicas são modelos construídos por nós, com todas as simplificações e as idealizações do caso, deveria nos aconselhar manter uma atitude prudente quanto à interpretação dos mesmos, ou seja, quanto ao conteúdo semântico que lhe atribuímos, particularmente no que concerne às partes dos modelos que são candidatas a representar entidades às quais não temos acesso empírico - van Fraassen mantém uma postura agnóstica em relação a essas últimas.

A simpatia de Vecchiato para com esse modo de encarar as teorias científicas transparece em seu livro e foi declarada de modo explícito em uma mensagem e-mail relativamente recente:

Penso (...) que o antirrealismo seja mais útil para quem pratica a ciência (e, por conseguinte, também para a ciência em si), por uma questão de economicidade e de elasticidade mental. Em breve, se aquilo que devo fazer é apenas 'salvar as aparências', isso requer menos esforço se comparado com uma posição que, independentemente daquilo que se diz, exige mais de mim. Se essa me oferecesse mais, então poderíamos discutir; mas não parece ser esse o caso... Em segundo lugar, se me acostumo a pensar em termos de entidades reais, acho que existe o risco de cristalizar-se em conceitos ligados às teorias. O exemplo clássico é o dualismo 'onda-partícula', que não tem motivo de existir na física quântica. Pode ser prático até um certo ponto, mas decorre de teorias anteriores e faz referência a entidades que apenas nessas últimas são matematicamente bem definidas; ademais, provoca inclusive uma grande confusão. Concordar que se trata de modelos matemáticos que descrevem determinados fenômenos torna inclusive muito mais fácil (para mim) aceitar que esses possam futuramente ser substituídos (mensagem e-mail de 10 de outubro de 2018) ${ }^{2}$

Manter uma postura crítica em relação àquilo que fazemos e pensamos e a tudo aquilo que se encontra ao nosso redor é sempre uma atitude saudável e louvável, ainda mais em tempos como os atuais. Nos cursos de graduação em física, contudo, não parece ser essa uma

\footnotetext{
${ }^{2} \mathrm{O}$ debate entre realismo e antirrealismo em filosofia da ciência caracteriza essa área de estudos desde que a mesma se constituiu como disciplina autônoma, há mais ou menos cem anos. Mas se insere em uma tradição antiga tanto quanto a própria filosofia. Ao leitor que fosse interessado em conhecer um pouco mais sobre o assunto, permito-me sugerir começar pelas entradas sobre empirismo lógico, realismo científico e empirismo construtivo da Stanford Encyclopedia of Philosophy (plato.stanford.edu), todas elas bem claras e exaustivas, redigidas por importantes filósofos da ciência contemporâneos. A bibliografia apresentada no final de cada uma delas é extremamente útil para quem eventualmente queira aprofundar o tema.
}

atitude comum em relação à disciplina, nem mesmo por parte de quem a ensina. Por isso, obras como aquela objeto desta resenha são extremamente bem-vindas e a leitura de Variational Approach to Gravity Field Theories vivamente recomendada.

\section{Agradecimentos}

Registro aqui meu agradecimento ao Dr Alberto Vecchiato (Osservatorio Astrofisico di Torino-INAF, Turim, Itália), que leu a presente resenha e autorizou a citação dos trechos de mensagens e-mail nela contidas. Grazie Alberto. Gostaria ainda de agradecer aos pareceristas anônimos da Revista pelos comentários e sugestões enriquecedores à primeira versão deste texto.

\section{Referências}

[1] A. Vecchiato, Variational Approach to Gravity Field Theories - From Newton to Einstein and Beyond (Springer, Cham, 2017), 1 ${ }^{\mathrm{a}}$ ed., $361 \mathrm{p}$.

[2] B.C. van Fraassen, The Scientific Image (Clarendon Press, Oxford, 1980), $1^{\text {a }}$ ed., 235 p. 